\title{
Determination of the load-independent hardness by analyzing the nanoindentation loading curves: A case study on fused silica
}

\author{
Yunbiao DUAN ${ }^{a}$, Danyu JIANG ${ }^{b, *}$, Jin $\mathrm{HU}^{a}$ \\ ${ }^{a}$ Faculty of Materials Science and Engineering, Kunming University of Science and \\ Technology, Kunming 650093, China \\ ${ }^{b}$ State Key Laboratory of High Performance Ceramics and Superfine Microstructure, \\ Shanghai Institute of Ceramics, Shanghai 200050, China
}

Received: August 18, 2019; Accepted: October 7, 2019

(C) The Author(s) 2019.

\begin{abstract}
The nanoindentation loading curves measured on fused silica were analyzed based on the theoretical relationship derived by Malzbender et al. (J Mater Res 2000, 15: 1209-1212). It was found that the ratio of the applied load to the square of the displacement, $P /\left(h+h_{\mathrm{d}}\right)^{2}$, does not keep constant during loading segment of the nanoindentation test. Considering the existence of the indentation size effect, an empirical method for the determination of the load-independent hardness by analyzing the nanoindentation loading curves was proposed.
\end{abstract}

Keywords: nanoindentation; loading curve; indentation size effect (ISE); fused silica

\section{Introduction}

It has been generally suggested that the loading portion of the load-displacement curve obtained during nanoindentation test, with ideally sharp conical indenter (e.g., the Berkovich indenter), can be well described by [1-4]:

$$
P=\alpha h^{2}
$$

where $P$ is the indentation load, $h$ is the indenter displacement, and the proportionality constant $\alpha$ depends on the material tested as well as the type of indenter. By writing the total indentation depth $h$ as the sum of the contact depth $h_{\mathrm{c}}$ and the displacement of the surface at the perimeter of the contact $h_{\mathrm{s}}$ (Fig. 1(a)), Malzbender et al. [5] derived an explicit expression for

\footnotetext{
* Corresponding author.

E-mail: dyjiang@mail.sic.ac.cn
}

the constant $\alpha$ :

$$
\alpha=E_{\mathrm{r}}\left(\frac{1 \pi}{\sqrt{24.5}} \sqrt{\frac{E_{\mathrm{r}}}{H}}+\varepsilon \sqrt{\frac{-}{4}} \sqrt{\frac{H}{E_{\mathrm{r}}}}\right)^{-2}
$$

where $\varepsilon$ is an indenter geometrical constant which takes a value of 0.75 for the Berkovich indenter [6], $E_{\mathrm{r}}$ is the reduced Young's modulus given by

$$
\frac{1}{E_{\mathrm{r}}}=\frac{1-v^{2}}{E}+\frac{1-v_{\mathrm{I}}^{2}}{E_{\mathrm{I}}}
$$

where $E$ and $v$ are Young's modulus and Poisson's ratio, respectively, of the indented specimen, and $E_{\mathrm{I}}=$ $1171 \mathrm{GPa}$ and $v_{\mathrm{I}}=0.07$ are those of the diamond indenter [6]. $H$ is the hardness defined as

$$
H=\frac{P}{A_{\mathrm{c}}}=\frac{P}{24.5 h_{\mathrm{c}}^{2}}
$$

In order to take into account the fact that a real indenter is never perfect due to some tip rounding (Fig. 
1(b)), Malzbender et al. [5] further suggested that the term $h^{2}$ in Eq. (1) should be replaced with $\left(h+h_{\mathrm{d}}\right)^{2}$, where $h_{\mathrm{d}}$ is called the effective truncation length of the indenter tip and its physical meaning is explained in Fig. 1(b). Thus, the load-displacement relation can be finally described as

$P=E_{\mathrm{r}}\left(\frac{1 \pi}{\sqrt{24.5}} \sqrt{\frac{E_{\mathrm{r}}}{H}}+\varepsilon \sqrt{\frac{-}{4}} \sqrt{\frac{H}{E_{\mathrm{r}}}}\right)^{-2}\left(h+h_{\mathrm{d}}\right)^{2}$

Equation (5) predicts that $P /\left(h+h_{\mathrm{d}}\right)^{2}$ should be a constant during the loading segment of a nanoindentation test. However, such a prediction has been verified only based on finite element simulation [5,7] and, up to now, little experimental verification has been conducted. Further, as mentioned by Malzbender et al. themselves [5], one of the most important assumptions in deriving Eq. (5) is that the hardness can be treated to be a constant, independent of indentation depth, despite the fact that indentation size effect (ISE) in the measured hardness is known to occur. Thus, in this communication, the nanoindentation data obtained on fused silica were analyzed to examine the applicability of Eq. (5) in describing the nanoindentation loading curves. By taking the indentation size effect into account, an empirical method for determining the load-independent hardness based on Eq. (5) was proposed.

\section{Experimental}

A commercial fused silica slide was used as the test sample. Fused silica is a reference material widely adopted in experimental verifications of nanoindentation theories [6,8-10]. Considering Young's modulus and Poisson's ratio might be generally expected to remain constants with scale, the literature reported data for fused silica, $E=72 \mathrm{GP}$ and $v=0.17$ were adopted for the present study.

Nanoindentation tests on fused silica were carried out using a Berkovich diamond tip with a commercial

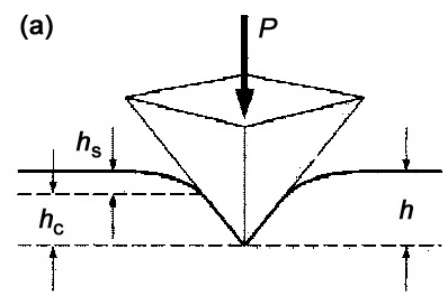

(b)

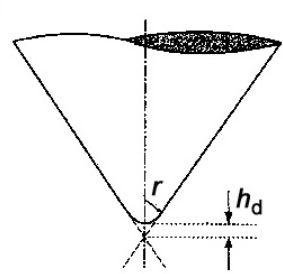

Fig. 1 Schematic diagrams showing (a) $h=h_{\mathrm{c}}+h_{\mathrm{s}}$ and (b) the geometry of a rounded indenter tip. nanoindenter (Nano Indenter G200, Aglient, Santa Clara, CA, USA). For each test, the indenter was linearly loaded to the prescribed maximum value, ranging from 50 to $400 \mathrm{mN}$, within $10 \mathrm{~s}$, held at the maximum load for $10 \mathrm{~s}$, and then unloaded linearly within $10 \mathrm{~s}$.

Figure 2 shows a typical load-displacement curve measured with a maximum load of $100 \mathrm{mN}$.

\section{Results and discussion}

Using Eq. (5) to describe the experimentally measured loading curves needs to know the value of the effective truncation length $h_{\mathrm{d}}$, which can be estimated using the following relation [11-14]:

$$
S=\beta\left(h_{\mathrm{c}}+h_{\mathrm{d}}\right)
$$

where $S$ is the contact stiffness and $\beta$ is a constant dependent on the reduced Young's modulus. Equation (6) predicts a linear relationship between $S$ and $h_{\mathrm{c}}$ and $h_{\mathrm{d}}$ can be estimated easily from the intercept.

The unloading portion of each measured loaddisplacement curve was analyzed according to the traditional Oliver-Pharr method [6] to yield the contact stiffness $S$ and the contact depth $h_{\text {c }}$ corresponding to each prescribed maximum load and the results are shown in Fig. 3. As can be seen, a good linear relationship exists between these two parameters, being in good agreement with Eq. (6). Then $h_{\mathrm{d}}$ was calculated to be $22.09 \mathrm{~nm}$ from the best-fit results with Eq. (6).

Using $h_{\mathrm{d}}=22.09 \mathrm{~nm}$, the $P /\left(h+h_{\mathrm{d}}\right)^{2}$ value for each experimental datum in the loading portion of each measured load-displacement curve was calculated and the results are shown in Fig. 4. Clearly, the resultant

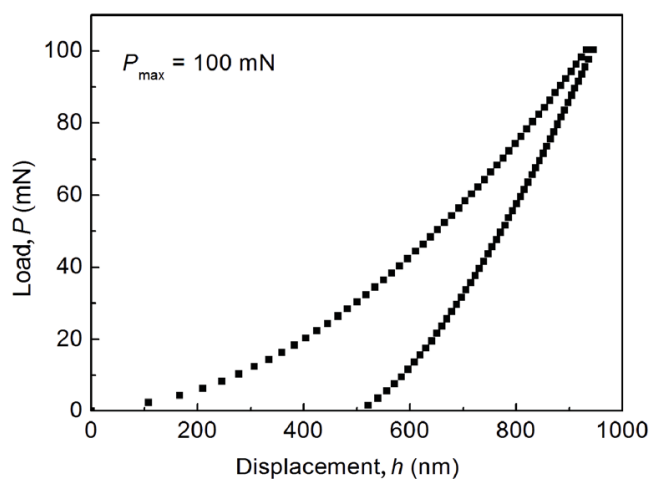

Fig. 2 Typical load-displacement curve measured for fused silica $\left(P_{\max }=100 \mathrm{mN}\right)$. 


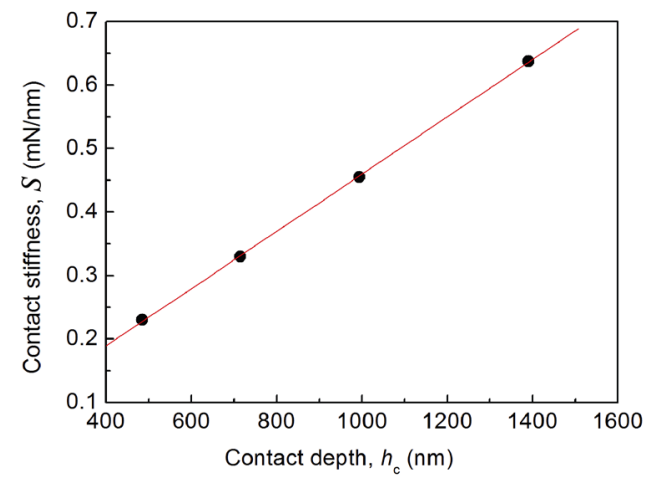

Fig. 3 Relationship between the contact stiffness $S$ and the contact depth $h_{\mathrm{c}}$. The solid line is obtained by regression analysis of the experimental data.

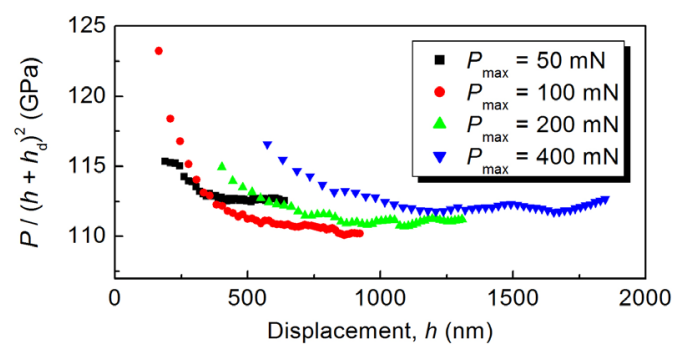

Fig. 4 Experimentally determined $P /\left(h+h_{\mathrm{d}}\right)^{2}$ as functions of displacement $h$ for different maximum load $\left(h_{\mathrm{d}}=22.09 \mathrm{~nm}\right)$.

$P /\left(h+h_{\mathrm{d}}\right)^{2}$ exhibits a decreasing tendency with $h$, especially within the small displacement (low load) region.

Noting that, in Eq. (5), $\varepsilon=0.75$ is a constant dependent only on the indenter geometry and, as mentioned above, Young's modulus might be generally expected to remain constant with scale, thus the decreasing tendency in $P /\left(h+h_{\mathrm{d}}\right)^{2}$ shown in Fig. 4 seems to imply that, if Eq. (5) is really suitable for describing the nanoindentation loading curve, the hardness $H$ included in Eq. (5) cannot be treated as a constant. In fact, the load dependence of the measured hardness has been frequently observed for different materials $[15,16]$. There is reason to believe that such a load dependence may also exist during the loading segment of a nanoindentation test.

In order to confirm this idea, the hardness $H$ was calculated as functions of indentation load $P$ based on Eq. (5) using the values of $P /\left(h+h_{\mathrm{d}}\right)^{2}$ given in Fig. 4. The results are shown in Fig. 5. Clearly, the calculated hardness exhibits a significant load dependence.

The load dependency of the measured hardness, i.e., ISE, has been widely studied and some phenomenological explanations for the origin of the ISE have been proposed [15-18]. It has been found that a second-order

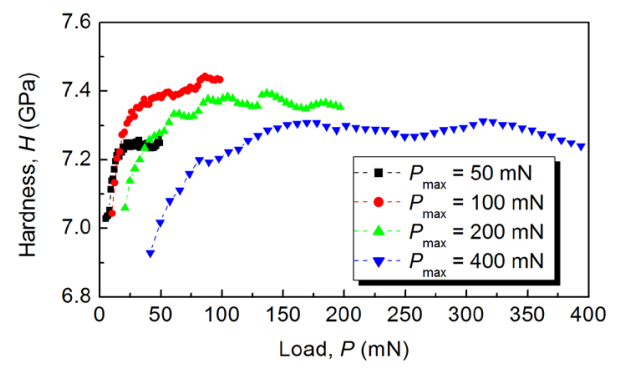

Fig. 5 Load dependency of the hardness calculated based on Eq. (5) using measured $P /\left(h+h_{\mathrm{d}}\right)^{2}$.

polynomial is sufficiently suitable for describing the relationship between the test load $P$ and the contact depth $h_{\mathrm{c}}[16,19,20]$ :

$$
P=a_{0}+a_{1} h_{\mathrm{c}}+a_{2} h_{\mathrm{c}}^{2}
$$

where $a_{0}, a_{1}$, and $a_{2}$ are constants. Especially, the coefficient $a_{2}$ is considered to be related with the load-independent hardness $H_{\mathrm{T}}$ of the test material:

$$
H_{\mathrm{T}}=k a_{2}
$$

where $k$ is a constant dependent on the indenter geometry. For Berkovich indenter, $k=1 / 24.5$.

Using the values of the measured hardness $H$ given in Fig. 5, the contact depth $h_{\mathrm{c}}$ corresponding to each datum point is calculated with Eq. (4) and the result is shown as a function of the load in Fig. 6. The solid line in this plot is obtained by a conventional polynomial regression according to Eq. (7). Clearly, Eq. (7) is proven sufficiently suitable for the representation of the data.

Using the best-fit value of $a_{2}, a_{2}=1.7447 \times 10^{-4}$ $\mathrm{mN} / \mathrm{nm}^{2}$, the true hardness of the fused silica can be determined from Eq. (8) to be $7.12 \mathrm{GPa}$, which is somewhat smaller compared with the reported values of the measured hardness, about $8.5 \mathrm{GPa}[6,21]$. This may be understood by noting that, in most cases $[16,19,20]$, the load-independent hardness determined with Eqs. (7) and (8) is always smaller than the load-dependent hardness value calculated with Eq. (4).

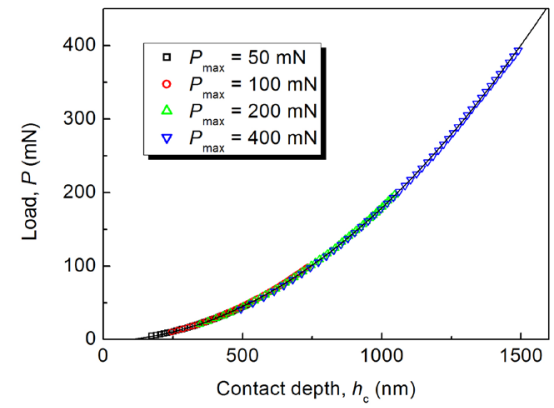

Fig. 6 Relationship between load $P$ and contact depth $h_{\mathrm{c}}$ calculated with the experimental data given in Fig. 5. 


\section{Concluding remarks}

Based on the above analyses, it may be concluded that:

(1) The hardness $H$ included in Eq. (5) may not be treated as a constant. As a result, the measured $P /(h+$ $\left.h_{\mathrm{d}}\right)^{2}$ exhibits a significant variation with displacement $h$.

(2) Equation (5) can be used to determine the load dependence of the hardness $H$ and the relationship between the contact depth and the applied load during the loading segment of a nanoindentation test. The latter can then be used to determine the loadindependent hardness of the test material.

It should be pointed out that the analyses conducted in the present study are still somewhat simple and, at least, further studies should be carried out to consider the effect of other parameters included in Eq. (5), the indenter geometry constant $\varepsilon$ and the effective truncation length $h_{\mathrm{d}}$, on the reliability of the loadindependent hardness determination.

\section{References}

[1] Hainsworth SV, Chandler HW, Page TF. Analysis of nanoindentation load-displacement loading curves. J Mater Res 1996, 11: 1987-1995.

[2] Zeng KY, Rowcliffe D. Analysis of penetration curves produced by sharp indentations on ceramic materials. Philos Mag A 1996, 74: 1107-1116.

[3] Cheng YT, Cheng CM. Relationships between hardness, elastic modulus, and the work of indentation. Appl Phys Lett 1998, 73: 614-616.

[4] Fischer-Cripps AC. Illustrative analysis of load-displacement curves in nanoindentation. J Mater Res 2007, 22 : 3075-3086.

[5] Malzbender J, de With G, den Toonder J. The $P-h^{2}$ relationship in indentation. J Mater Res 2000, 15: 1209-1212.

[6] Oliver WC, Pharr GM. An improved technique for determining hardness and elastic modulus using load and displacement sensing indentation experiments. J Mater Res 1992, 7: 1564-1583.

[7] Jha KK, Suksawang N, Agarwal A. Analytical method for the determination of indenter constants used in the analysis of nanoindentation loading curves. Scripta Mater 2010, 63 : 281-284.

[8] Gadelrab KR, Bonilla FA, Chiesa M. Densification modeling of fused silica under nanoindentation. $J$ NonCryst Solids 2012, 358: 392-398.

[9] Park JS, Lee YH, Kim Y, et al. Prediction of bluntness for pyramidal indenters from nanoindentation curves. Surf Coat Technol 2012, 211: 148-151.

[10] Jia YF, Cui YY, Xuan FZ, et al. Comparison between single loading-unloading indentation and continuous stiffness indentation. RSC Adv 2017, 7: 35655-35665.

[11] Bull SJ, Page TF, Yoffe EH. An explanation of the indentation size effect in ceramics. Philos Mag Lett 1989, 59: $281-288$.

[12] Herrmann K, Jennett NM, Wegener W, et al. Progress in determination of the area function of indenters used for nanoindentation. Thin Solid Films 2000, 377-378: 394 400.

[13] Sawa T, Tanaka K. Simplified method for analyzing nanoindentation data and evaluating performance of nanoindentation instruments. $J$ Mater Res 2001, 16: 3084-3096.

[14] Gong JH, Miao HZ, Peng ZJ. On the contact area for nanoindentation tests with Berkovich indenter: Case study on soda-lime glass. Mater Lett 2004, 58: 1349-1353.

[15] Gong JH, Wu JJ, Guan ZD. Examination of the indentation size effect in low-load Vickers hardness testing of ceramics. J Eur Ceram Soc 1999, 19: 2625-2631.

[16] Peng ZJ, Gong JH, Miao HZ. On the description of indentation size effect in hardness testing for ceramics: Analysis of the nanoindentation data. J Eur Ceram Soc 2004, 24: 2193-2201.

[17] Fröhlich F, Grau P, Grellmann W. Performance and analysis of recording microhardness tests. Phys Stat Sol (a) 1977, 42: 79-89.

[18] Li H, Bradt RC. The microhardness indentation load/size effect in rutile and cassiterite single crystals. J Mater Sci 1993, 28: 917-926.

[19] Jiang DY. Recent progresses in the phenomenological description for the indentation size effect in microhardness testing of brittle ceramics. $J A d v$ Ceram 2012, 1: 38-49.

[20] Shao LQ, Jiang DY, Gong JH. Nanoindentation characterization of the hardness of zirconia dental ceramics. $A d v$ Eng Mater 2013, 15: 704-707.

[21] Keryvin V, Charleux L, Hin R, et al. Mechanical behaviour of fully densified silica glass under Vickers indentation. Acta Mater 2017, 129: 492-499.

Open Access This article is licensed under a Creative Commons Attribution 4.0 International License, which permits use, sharing, adaptation, distribution and reproduction in any medium or format, as long as you give appropriate credit to the original author(s) and the source, provide a link to the Creative Commons licence, and indicate if changes were made.

The images or other third party material in this article are included in the article's Creative Commons licence, unless indicated otherwise in a credit line to the material. If material is not included in the article's Creative Commons licence and your intended use is not permitted by statutory regulation or exceeds the permitted use, you will need to obtain permission directly from the copyright holder.

To view a copy of this licence, visit http://creativecommons.org/licenses/by/4.0/. 